\title{
Communication
}

\section{Synthesis and Bioactivity of Thiazolethioacetamides as Potential Metallo- $\beta$-Lactamase Inhibitors}

\author{
Yi-Lin Zhang ${ }^{1, *}$, Yong Yan ${ }^{1}$, Xue-Jun Wang ${ }^{1}$ and Ke-Wu Yang ${ }^{2}$ \\ 1 College of Biology Pharmacy and Food Engineering, Shangluo University, Shangluo 726000, China; \\ yananan@yeah.net (Y.Y.); xuejunwangd@163.com (X.W.) \\ 2 Key Laboratory of Synthetic and Natural Functional Molecule Chemistry of Ministry of Education, College of \\ Chemistry and Materials Science, Northwest University, Xi'an 710127, China; kwyang@nwu.edu.cn \\ * Correspondence: 233049@slxy.edu.cn
}

Received: 2 February 2020; Accepted: 23 February 2020; Published: 26 February 2020

check for updates

\begin{abstract}
Metallo- $\beta$-lactamase $(\mathrm{M} \beta \mathrm{Ls})$ mediated antibiotic resistance seriously threatens the treatment of bacterial diseases. Recently, we found that thioacetamides can be a potential M $\beta \mathrm{L}$ inhibitor skeleton. In order to improve the information of the skeleton, twelve new thiazolethioacetamides were designed by modifying the aromatic substituent. Biological activity assays identify the thiazolethioacetamides can inhibit ImiS with $\mathrm{IC}_{50}$ values of 0.17 to $0.70 \mu \mathrm{M}$. For two of them, the $\mathrm{IC}_{50}$ values against VIM-2 were 2.2 and $19.2 \mu \mathrm{M}$, which is lower than in our previous report. Eight of the thiazolethioacetamides are able to restore antibacterial activity of cefazolin against E.coli-ImiS by 2-4 fold. An analysis of the structure-activity relation and molecule docking show that the style and position of electron withdrawing groups in aromatic substituents play a crucial role in the inhibitory activity of thiazolethioacetamides. These results indicate that thiazolethioacetamides can serve as a potential skeleton of $\mathrm{M} \beta \mathrm{L}$ inhibitors.
\end{abstract}

Keywords: thiazolethioacetamides; metallo- $\beta$-lactamase; inhibitor

\section{Introduction}

Antibacterial resistance has now reached alarming levels worldwide. As classical antibiotics, $\beta$-Lactam antibiotics account for over $65 \%$ in clinical settings because of their effective antibacterial activity and selectivity [1]. Unfortunately, like other antibacterial drugs, the overuse and misuse of $\beta$-lactam antibiotics accelerates the emergence of drug-resistant strains [2]. The main mechanisms of $\beta$-lactam antibiotic resistance are due to the production of $\beta$-lactamases by bacteria, the resistant strains of which can rapidly spread on a global scale [3]. The $\beta$-lactamases can hydrolyze the $\beta$-lactam ring, which leads to a loss of antibacterial activity in antibiotics including penicillin, cephalosporins and carbapenems [4].

Based on amino acid sequence homologies, $\beta$-lactamases have been categorized into serine $\beta$-lactamases (S $\beta$ Ls) and metallo- $\beta$-lactamases $(\mathrm{M} \beta \mathrm{Ls})$ [5]. S $\beta$ Ls use serine as an active site, existing in successful clinical inhibitors such as sulbactam, tazobactam and clavulanic acid [6]. M $\beta$ Ls can be further categorized into subclasses B1-B3, which utilize either one or two equivalents of $\mathrm{Zn}(\mathrm{II})$ as the active site [7]. M $\beta$ Ls currently threaten almost all $\beta$-lactamase antibiotics in treating bacterial infection. The rapid diffusion of NDM-1-producing K.pneumoniae isolates is a striking example [8]. Because of variations in $\mathrm{M} \beta \mathrm{L}$ structures, clinical $\mathrm{M} \beta \mathrm{L}$ inhibitors are still lacking. Over the past several years, the literature has provided various approaches for overcoming antibiotic resistance and a number of $\mathrm{M} \beta \mathrm{L}$ inhibitors have been designed including sulfonamides, dicarboxylate, $\beta$-lactams, cyclic boronates and multivalent chelators [1,9-11]. Sulfur-containing compounds occupy an important position in the 
design of $\mathrm{M} \beta \mathrm{L}$ inhibitors because the sulfur atom can reduce the $\mathrm{M} \beta \mathrm{Ls}$ activity by binding to the zinc ions which are enzyme active center and replacing the bridging water molecules [12,13].

Recently, our group has reported that thioacetamide derivatives exhibit biological activity which may inhibit M $\beta$ Ls [14-17]. In addition, some of the thioacetamides showed broad-spectrum inhibitory activity against all three subclasses of M $\beta$ Ls. In order to develop the structure-activity relationships, twelve new thiazolethioacetamides were synthesized and characterized. The inhibitory activity was evaluated against M $\beta$ Ls VIM-2, ImiS, and L1, which are representatives of the B1, B2 and B3 subclasses of $M \beta L$ s, respectively. The ability of these thiazolethioacetamides to defend against the resistant bacterial strain was evaluated by a minimum inhibitory concentrations (MICs) assay. Furthermore, molecular docking was employed when studying the possible interactions between the inhibitors and the corresponding $\mathrm{M} \beta \mathrm{Ls}$.

\section{Results}

To acquire effective $M \beta L$ inhibitors, twelve diaryl-substituted thiazolethioacetamides were synthesized as shown in the Supporting Information and characterized by NMR and MS. The yields of the compounds ranged from $56.9 \%$ to $87.4 \%$ and the structures of these compounds are shown in Figure 1.
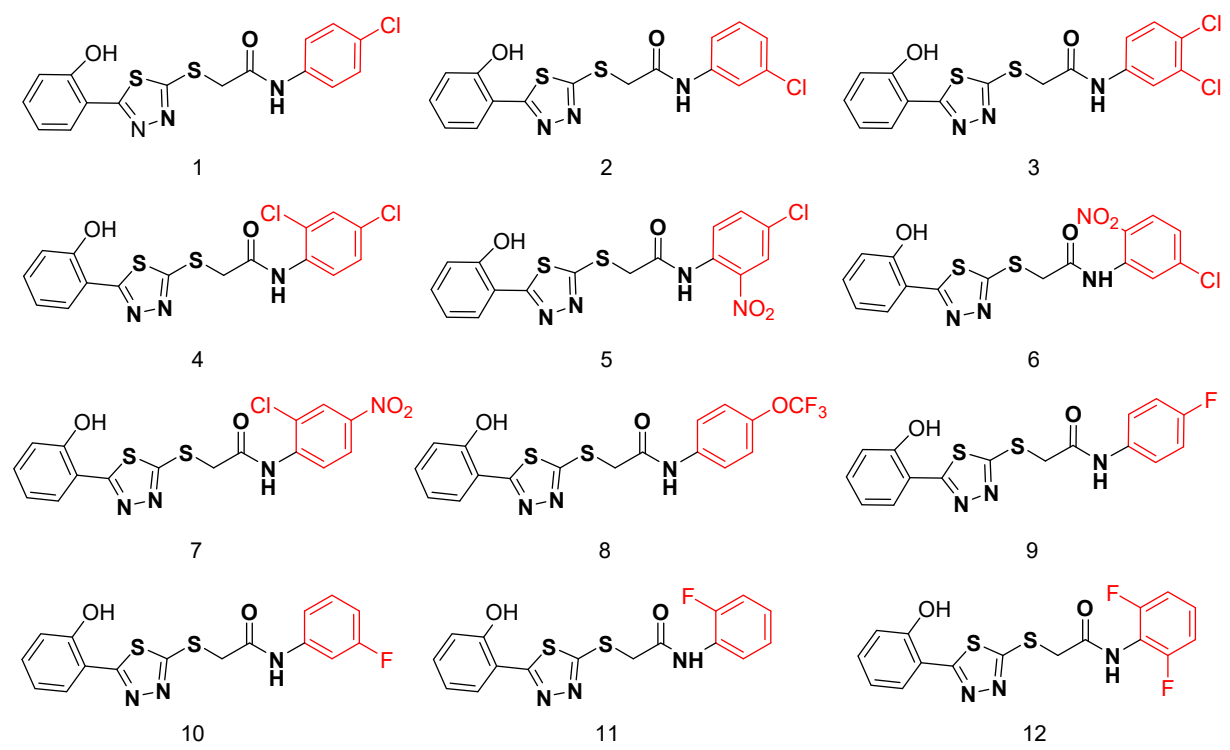

Figure 1. Structures of the synthesized thiazolethioacetamides.

To test the inhibitory activity of compounds 1-12 against M $\beta$ Ls, three representative M $\beta$ Ls, VIM-2 (B1), ImiS (B2), and L1 (B3), were chosen for evaluation. The $\mathrm{IC}_{50}$ values of the compounds against $\mathrm{M} \beta$ Ls with cefazolin as the substrate are listed in Table 1 . The inhibition studies indicated that the thiazolethioacetamides had specific inhibitory activity against ImiS and VIM-2, though none of them showed any activity against L1 until the inhibitor concentration reached $1 \mathrm{mM}$.

Table 1. $\mathrm{IC}_{50}$ values of thiazolethioacetamides against M $\beta$ Ls ImiS and VIM-2.

\begin{tabular}{cccccc}
\hline \multirow{2}{*}{ Compds } & \multicolumn{2}{c}{ IC $_{\mathbf{5 0}}(\boldsymbol{\mu M})$} & \multirow{2}{*}{ Compds } & \multicolumn{2}{c}{ IC $_{\mathbf{5 0}}(\boldsymbol{\mu M})$} \\
& ImiS & VIM-2 & & ImiS & VIM-2 \\
\hline 1 & 0.58 & - & 7 & 0.42 & - \\
2 & 0.53 & - & 8 & 0.31 & 2.2 \\
3 & 0.69 & - & 9 & 0.46 & - \\
4 & 0.58 & - & 10 & 0.61 & - \\
5 & 0.17 & - & 11 & 0.68 & - \\
6 & 0.36 & - & 12 & 0.70 & 19.2 \\
\hline
\end{tabular}


It can be observed that compounds 1-12 exhibited an ability to inhibit ImiS with an $\mathrm{IC}_{50}$ value range of $0.17-0.70 \mu \mathrm{M}$, while compounds 8 and 12 also showed inhibitory activity against VIM-2 with an $\mathrm{IC}_{50}$ value 2.2 and $19.2 \mu \mathrm{M}$. When the substituent was at the p-position of the benzene ring, compound 8 with trifluoromethoxy had a lower $\mathrm{IC}_{50}$ value of $0.31 \mu \mathrm{M}$ for ImiS than compound 1 containing chlorine $(0.58 \mu \mathrm{M})$ and compound 9 containing fluorine $(0.46 \mu \mathrm{M})$. The number and position of chlorine atoms had little effect on the inhibitory activity of compounds 1-4 which had almost the same $\mathrm{IC}_{50}$ value. However, with compounds 9-12, fluorine in the p-position improved the ability of the compounds to inhibit ImiS. In addition, compounds 5-7 with chlorine and nitro inhibited ImiS with a better $\mathrm{IC}_{50}$ value range of $0.17-0.42 \mu \mathrm{M}$, whilst compound 5 gave the lowest $\mathrm{IC}_{50}$ value of $0.17 \mu \mathrm{M}$ among all the compounds. The nitro group may bind selectively with the active site of the enzyme.

The capacity of thiazolethioacetamides to restore the antibacterial activity of cefazolin against E.coli BL21 (DE3) cells expressing ImiS and VIM-2 was investigated by determining the minimum inhibitory concentrations (MIC). No compounds had synergistic bacteriostatic effect on E.coli and E.coli-VIM-2 with cefazolin, and the results to inhibit E.coli-ImiS are shown in Table 2. Compounds 5-12 resulted in a 2-4 fold reduction of MIC value for E.coli-ImiS in vivo. Inhibitors 1-4 did not change the MIC value relative to the blank control.

Table 2. Minimum inhibitory concentrations (MIC) $(\mu \mathrm{g} / \mathrm{mL})$ value of cefazolin against $E$. coli-ImiS in the presence of thiazolethioacetamides.

\begin{tabular}{cccccc}
\hline Compds & E.coli-ImiS & Compds & E.coli-ImiS & Compds & E.coli-ImiS \\
\hline Blank & 20 & 5 & 10 & 10 & 5 \\
1 & 20 & 6 & 10 & 11 & 10 \\
2 & 20 & 7 & 10 & 12 & 10 \\
3 & 20 & 8 & 5 & & \\
4 & 20 & 9 & 5 & & \\
\hline
\end{tabular}

In order to explore how the inhibitors bind to $\mathrm{M} \beta \mathrm{Ls}$, compounds 8 and 12 were docked into the active pocket of VIM-2 (PDB code 4NQ2), whilst 5 and 8 were docked into CphA (PDB code 2QDS). CphA is an alternative of ImiS which has not been crystallized, because they share a $96 \%$ similar sequence. Low-energy conformations (the top ranked conformations) are shown in Figure 2, with binding energies of $-6.97,-6.59,-12.64$ and $-8.14 \mathrm{kcal} / \mathrm{mol}$ for the VIM-2/8, VIM-2/12, CphA/5 and $\mathrm{CphA} / 8$ complexes, respectively. The molecule docking result reveals the same trend in respect of the $\mathrm{IC}_{50}$ values.

According to the bonding mode of the complexes, the docking binding energy of the CphA/inhibitors (ImiS/inhibitors) is significantly lower. This is most likely due to a second $\mathrm{Zn}$ (II) ion in VIM-2 resulting in a smaller activity pocket. The bonding energy of VIM-2/8 is lower than that of VIM-2/12, which is probably because the different interactions with Zn(II). In the VIM-2/8 complex, the phenolic hydroxyl group forms hydrogen bonds with $\mathrm{Zn}$ (II) and Asn210, with a distance of 3.04 and $2.25 \AA$, respectively. Moreover, the nitrogen in the thiazole ring and the second $\mathrm{Zn}$ (II) interacts with Asp118, whilst the nitrogen in the amido linkage and the oxygen in the trifluoromethoxy group interact with Tyr67 and Arg205, respectively. However, compound 12 exerts inhibitory action only by interacting with oxygen in the amido linkage to form hydrogen bonds with the two $\mathrm{Zn}$ (II), with an average distance of $2.29 \AA$. In complex CphA/inhibitors, the phenolic hydroxyl group of CphA/8 interacts with $\mathrm{Zn}(\mathrm{II})$ and Asp120 with a mean distance of $2.94 \AA$, whilst the oxygen in the amido group forms hydrogen bonds with Asp264. In complex CphA/5, the phenolic hydroxyl group interacts with Asp264 and Gln68. The oxygen in the nitro group forms hydrogen bonds with $\mathrm{Zn}(\mathrm{II})$, with a distance of $1.88 \AA$, and His 263 , with a distance of $2.70 \AA$, whilst oxygen in the amido group forms bonds with Lys224. The variety of bonds formed increases the affinity with $\mathrm{M} \beta \mathrm{Ls}$, which results in the lowest binding energy of $-12.64 \mathrm{kcal} / \mathrm{mol}$. 


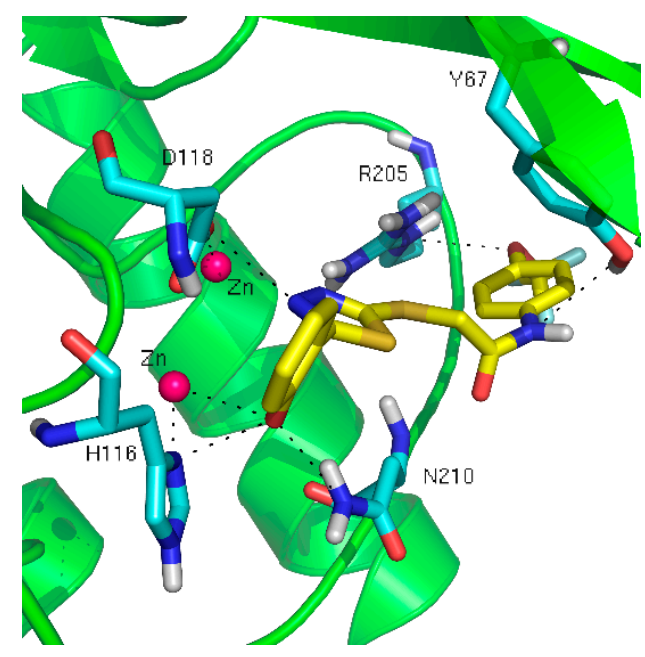

(a)

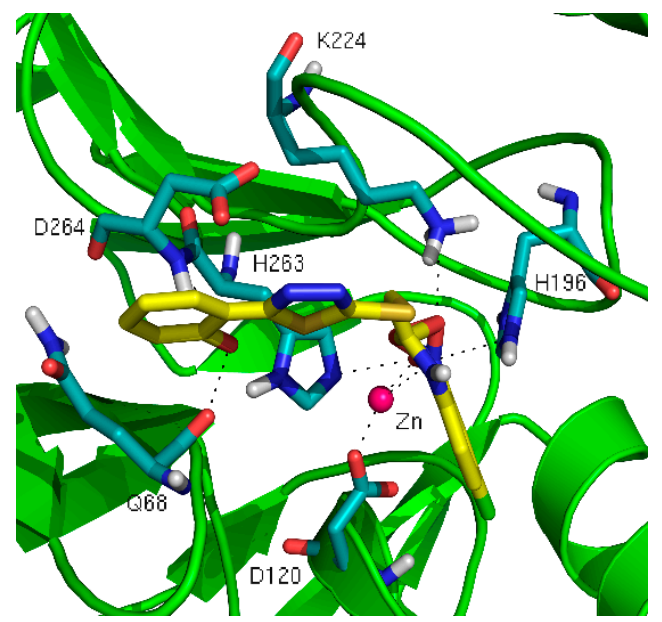

(c)

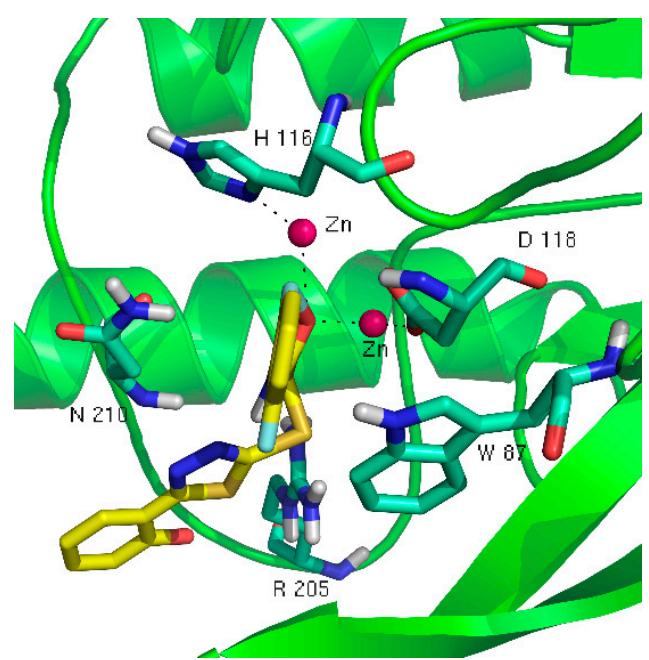

(b)

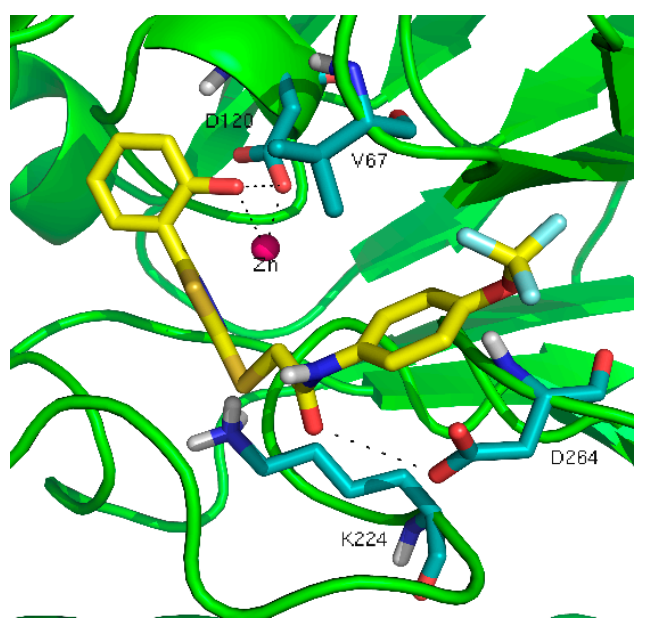

(d)

Figure 2. Low energy conformations of compounds 8 (a) and 12 (b) docked into the active site of VIM-2 (PDB code 4NQ2), 5 (c) and 8 (d) docked into the active site of CphA (PDB code 2QDS).

\section{Discussion}

The twelve thiazolethioacetamides exhibit different abilities to inhibit ImiS and VIM-2 with the $\mathrm{IC}_{50}$ value range of $0.17-19.2 \mu \mathrm{M}$. A possible reason for this is that the kind and position of the substituents in the benzene ring greatly affected the affinity between the inhibitor molecule and M $\beta$ Ls. In line with our previous research [14-17], electron-absorbing groups have a greater ability to improve the affinity of inhibitors and $\mathrm{M} \beta \mathrm{Ls}$. The nitro group has been proven to be an effective zinc ligand in the complex of carboxypeptidase A/aromatic nitropropionic acid [18]. In a molecule docking assay, the nitro group of complex $\mathrm{CphA} / 5$ can interact with $\mathrm{Zn}$ (II) at short distances. This could be the reason why compounds 5-7 are more effective inhibitors against ImiS. Another factor to consider is the position of these compounds, which depends on the kinds of substituents. Through the analysis of the conformations, the o-position nitro of the benzene ring and the amide can make up a stable virtual six-membered ring which improves the biological activity of compounds 5 and 6 . In addition, the biological activity of triazolethioacetamides is better than that of thiazolethioacetamides, but thiazolethioacetamides have a greater potential to inhibit VIM-2. This information is valuable for the further development of $\mathrm{M} \beta \mathrm{L}$ inhibitors. 


\section{Materials and Methods}

General chemicals were purchased from TCI (Tokyo Chemical Industry, Tokyo, Japan) and were used without further purification. All antibiotics used were purchased from Sigma-Aldrich (Burlington, MO, USA). ${ }^{1} \mathrm{H}$ NMR and ${ }^{13} \mathrm{C}$ NMR spectra were recorded with a Bruker DRX $600 \mathrm{MHz}$ spectrometer (Bruker Daltonics Inc., Billerica, MA, USA) and a Bruker MicrOTOF-Q II mass spectrometer was used to detect the HRMS data.

\subsection{Synthesis and Characterization}

The synthetic route and spectrum information of the twelve thiazolethioacetamides are shown in the Supplementary Information. Briefly, N-substituted-2-chloroacetamides and 2-(5-mercapto-1,3,4-thiadiazol-2-yl)phenol were as previously reported [17]. A solution of 2-(5-mercapto-1,3,4-thiadiazol-2-yl)phenol and $\mathrm{K}_{2} \mathrm{CO}_{3}\left(3.6 \mathrm{mmol}\right.$ ) dissolved in $\mathrm{H}_{2} \mathrm{O}(15 \mathrm{~mL})$ was stirred for $30 \mathrm{~min}$. After $\mathrm{N}$-substituted-2 -chloroacetamides ( $3 \mathrm{mmol}$ ) was added, the reaction mixture was heated to reflux for $6 \mathrm{~h}$. The reaction mixture was cooled to RT and neutralized with $5 \mathrm{M} \mathrm{HCl}$ to a pH of approximately 7.0. The resulting white solid was collected by filtration, washed with $\mathrm{H}_{2} \mathrm{O}$ repeatedly $(3 \times 80 \mathrm{~mL})$ and dried in vacuo to obtain compounds 1-12.

\subsection{Determination of $I_{50}$ Values}

The enzyme inhibition activity assay was carried out on an Agilent-8453 UV-visible spectrometer. Control experiments verified that the $0.1 \%$ DMSO exhibited no inhibitory activity against the M $\beta$ Ls, therefore the final concentrations of DMSO were $0.1 \%$ to dissolve thiazolethioacetamides $1-12$ in the inhibition experiments and diluted with a $30 \mathrm{mM}$ Tris solution. Cefazolin (Sigma-Aldrich, Burlington, MO, USA), with a concentration of 20 to $140 \mu \mathrm{M}$, was taken as the substrate. The enzyme and inhibitor were premixed with the corresponding $\mathrm{M} \beta \mathrm{L}$ and the thiazolethioacetamides for $30 \mathrm{~min}$. The $\mathrm{IC}_{50}$ values were measured at $25{ }^{\circ} \mathrm{C}$ with the inhibitor concentrations of 0 and $1000 \mu \mathrm{M}$, and analyzed through $\mathrm{IC}_{50}$ calculation tool (AAT Bioquest Inc., sunnyvale, CA, USA).

\subsection{Determination of MIC Values}

According to the Clinical and Laboratory Standards Institute (CLSI) macrodilution (tube) broth method [19], MIC values were determined by using a Thermo Scientific Microplate Reader Multiskan FC. An amount of $1280 \mu \mathrm{g} / \mathrm{mL}$ antibiotics was prepared in $\mathrm{ddH}_{2} \mathrm{O}$ and the compounds 1-12 were dissolved in DMSO to $320 \mu \mathrm{g} / \mathrm{mL}$ solution. MH solution $(900 \mu \mathrm{L})$ and $100 \mu \mathrm{L}$ inhibitor solution were added to 2-11 holes of 96-well plates, and an additional $400 \mu \mathrm{L} \mathrm{MH}$ solution, $200 \mu \mathrm{L}$ inhibitor solution and antibiotic solution $(400 \mu \mathrm{L})$ were added to the first hole. An amount of $100 \mu \mathrm{L}$ mix solution was transferred to successive holes. The $100 \mu \mathrm{L}$ bacterial solution in $\mathrm{MH}$ medium was added to each hole. The final concentration of bacterial strains was $5 \times 10^{5} \mathrm{CFU}$ per mL. The 96-well plates were incubated at $37^{\circ} \mathrm{C}$ for $12 \mathrm{~h}$, and the results were the same as those in the prescribed 16 to $20 \mathrm{~h} .4 .4$ Docking Calculations.

Thiazolethioacetamides 5, 8 and 12 were selected as ligand to proceed Docking studies with CphA and VIM-2 by AutoDock 4.2 [20]. The crystal structures of protein were downloaded from the protein database (https://www.rcsb.org) [20]. CphA protein was centered at the location of $\mathrm{Zn}$ (II), while VIM-2 was centered at the middle of two $\mathrm{Zn}(\mathrm{II})$. The size of grid box was set to $80 \times 80 \times 80$, and the grid points space was at $0.375 \AA$. During the calculation, the mutation rate and the crossover probability were 0.02 and 0.8 , respectively. Meanwhile, other parameters were kept unchanged at the default values. Through the Lamarckian genetic algorithm, each complex produces fifty docking configurations. The lowest-energy (highest ranked) configurations will be further studied. 


\section{Conclusions}

In summary, twelve new thiazolethioacetamides were designed and synthesized. Biological activity assays indicate that all the compounds exhibited $\mathrm{IC}_{50}$ values ranging from 0.17 to $0.70 \mu \mathrm{M}$ against M $\beta \mathrm{L}$ ImiS, and two thiazolethioacetamides were able to inhibit VIM-2 with $\mathrm{IC}_{50}$ values of 2.2 and $19.2 \mu \mathrm{M}$. Eight thiazolethioacetamides could improve the bactericidal capacity of cefazolin to prevent E.coli-ImiS by $2-4$ fold. Through structure-activity relation and molecule docking, it was revealed that the electron-withdrawing group and position of the substituents are important factors to consider when determining the inhibitory capacity of thiazolethioacetamides. The information in this work is valuable for the further development of $\mathrm{M} \beta \mathrm{L}$ inhibitors.

Supplementary Materials: The following are available online at http://www.mdpi.com/2079-6382/9/3/99/s1. The synthetic route, ${ }^{1} \mathrm{H}$ NMR, ${ }^{13} \mathrm{C}$ NMR and HRMS spectra data of all the target compounds were provided in supporting information.

Author Contributions: Conceptualization and methodology, Y.-L.Z.; formal analysis, Y.Y.; data curation, X.-J.W.; supervision, K.-W.Y.; writing — original draft preparation, Y.-L.Z.; writing—review and editing, Y.Y. All authors have read and agreed to the published version of the manuscript.

Funding: This work was supported by the Natural Science Foundation of Shaanxi Province (2018JQ2070), the Scientific Research Plan Project by Educational Department of Shaanxi Province (18JK0250), the science and technology development fund of Zhang Shengyong academician (18YSZX002); the Natural Science Foundation of Shangluo University (16SKY021).

Acknowledgments: Thanks to all the funding and support. The inhibition study was carried out in key laboratory of synthetic and natural functional molecule chemistry of ministry of education at Northwest University. All the enzymes and bacteria used in the study were donated from Kewu Yang.

Conflicts of Interest: The authors declare no conflict of interest.

\section{References}

1. Docquier, J.D.; Mangani, S. An update on $\beta$-lactamase inhibitor discovery and development. Drug Resist. Update 2018, 36, 13-29. [CrossRef] [PubMed]

2. Baym, M.; Stone, L.K.; Kishony, R. Multidrug evolutionary strategies to reverse antibiotic resistance. Science 2016, 351, aad3292. [CrossRef] [PubMed]

3. Fisher, J.F.; Meroueh, S.O.; Mobashery, S. Bacterial resistance to $\beta$-lactam antibiotics: Compelling opportunism, compelling opportunity. Chem. Rev. 2005, 105, 395-424. [CrossRef] [PubMed]

4. Bush, K. Past and present perspectives on $\beta$-lactamases. Antimicrob. Agents Chemother. 2018, 62, 1076-1118. [CrossRef] [PubMed]

5. Bush, K.; Jacoby, G.A. Updated functional classification of $\beta$-lactamases. Antimicrob. Agents Chemother. 2010, 54, 969-976. [CrossRef] [PubMed]

6. Drawz, S.M.; Bonomo, R.A. Three decades of $\beta$-lactamase inhibitors. Clin. Microbiol. Rev. 2010, $23,160-201$. [CrossRef] [PubMed]

7. Bebrone, C. Metallo- $\beta$-lactamases (classification, activity, genetic organization, structure, zinc coordination) and their superfamily. Biochem. Pharmacol. 2007, 74, 1686-1701. [CrossRef] [PubMed]

8. González, L.J.; Bahr, G.; Nakashige, T.G.; Nolan, E.M.; Bonomo, R.A.; Vila, A.J. Membrane anchoring stabilizes and favors secretion of New Delhi metallo- $\beta$-lactamase. Nat. Chem. Biol. 2016, 12, 516-522. [CrossRef] [PubMed]

9. Christopeit, T.; Carlsen, T.J.; Helland, R.; Leiros, H.K. Discovery of novel inhibitor scaffolds against the metallo- $\beta$-lactamase VIM-2 by surface plasmon resonance (SPR) based fragment screening. J. Med. Chem. 2015, 58, 8671-8682. [CrossRef] [PubMed]

10. Decuyper, L.; Jukic, M.; Sosic, I.; Zula, A.; D’Hooghe, M.; Gobec, S. Antibacterial and $\beta$-lactamase inhibitory activity of monocyclic $\beta$-lactams. Med. Res. Rev. 2018, 38, 426-503. [CrossRef] [PubMed]

11. Chiou, J.; Wan, S.; Chan, K.F.; So, P.K.; He, D.; Chan, E.W.; Chan, T.H.; Wong, K.Y.; Tao, J.; Chen, S. Ebselen as a potent covalent inhibitor of New Delhi metallo- $\beta$-lactamase (NDM-1). Chem. Commun. 2015, 51, 9543-9546. [CrossRef] [PubMed] 
12. Büttner, D.; Kramer, J.S.; Klingler, F.M.; Wittmann, S.K.; Hartmann, M.R.; Kurz, C.G.; Kohnhäuser, D.; Weizel, L.; Brüggerhoff, A.; Frank, D.; et al. Challenges in the development of a thiol-based broad-spectrum inhibitor for metallo- $\beta$-lactamases. ACS Infect. Dis. 2017, 4, 360-372. [CrossRef] [PubMed]

13. Damblon, C.; Jensen, M.; Ababou, A.; Barsukov, I.; Papamicael, C.; Schofield, C.J.; Olsen, L.; Bauer, R.; Roberts, G.C.K. The inhibitor thiomandelic acid binds to both metal ions in metallo- $\beta$-lactamase and induces positive cooperativity in metal binding. J. Biol. Chem. 2003, 278, 29240-29251. [CrossRef] [PubMed]

14. Xiang, Y.; Chang, Y.N.; Ge, Y.; Kang, J.S.; Zhang, Y.L.; Liu, X.L.; Oelschlaeger, P.; Yang, K.W. Azolylthioacetamides as a potent scaffold for the development of metallo- $\beta$-lactamase inhibitors. Bioorg. Med. Chem. Lett. 2017, 27, 5225-5229. [CrossRef] [PubMed]

15. Zhai, L.; Zhang, Y.L.; Kang, J.S.; Oelschlaeger, P.; Xiao, L.; Nie, S.S.; Yang, K.-W. Triazolylthioacetamide: A valid scaffold for the development of New Delhi metallo- $\beta$-lactmase-1 (NDM-1) inhibitors. ACS Med. Chem. Lett. 2016, 7, 413-417. [CrossRef] [PubMed]

16. Zhang, Y.L.; Yan, Y.; Liang, L.F.; Feng, J.; Wang, X.J.; Li, L.; Yang, K.W. Halogen-substituted triazolethioacetamides as a potent skeleton for the development of metallo- $\beta$-lactamase inhibitors. Molecules 2019, 24, 1174. [CrossRef] [PubMed]

17. Zhang, Y.L.; Yang, K.W.; Zhou, Y.J.; LaCuran, A.E.; Oelschlaeger, P.; Crowder, M.W. Diaryl -substituted azolylthioacetamides: Inhibitor discovery of New Delhi metallo- $\beta$-lactamase-1 (NDM-1). ChemMedChem 2014, 9, 2445-2448. [CrossRef] [PubMed]

18. Wang, S.H.; Wang, S.F.; Xuan, W.; Zeng, Z.H.; Jin, J.Y.; Ma, J.; Tian, G.R. Nitro as a novel zinc-binding group in the inhibition of carboxypeptidase A. Bioorg. Med. Chem. 2008, 16, 3596-3601. [CrossRef] [PubMed]

19. Pereira da Cruz, R.; Sampaio de Freitas, T.; do Socorro Costa, M.; Lucas Dos Santos, A.T.; Ferreira Campina, F.; Pereira, R.L.S.; Bezerra, J.W.A.; Quintans-Júnior, L.J.; De Souza Araújo, A.A.; De Siqueira Júnior, J.P.; et al. Effect of $\alpha$-bisabolol and its $\beta$-cyclodextrin complex as tetk and nora efflux pump inhibitors in Staphylococcus aureus strains. Antibiotics 2020, 9, 28. [CrossRef] [PubMed]

20. Morris, G.M.; Huey, R.; Lindstrom, W.; Sanner, M.F.; Belew, R.K.; Goodsell, D.S.; Olson, A.J. Autodock4 and autodocktools4: Automated docking with selective receptor flexibility. J. Comput. Chem. 2009, 30, 2785-2791. [CrossRef] [PubMed]

(C) 2020 by the authors. Licensee MDPI, Basel, Switzerland. This article is an open access article distributed under the terms and conditions of the Creative Commons Attribution (CC BY) license (http://creativecommons.org/licenses/by/4.0/). 